\title{
Enric PORQUERES I GENE, Individu, personne et parenté en Europe
}

Anne Cadoret

\section{(2) OpenEdition}

\section{Journals}

Édition électronique

URL : http://journals.openedition.org/ress/3695

DOI : $10.4000 /$ ress.3695

ISBN : $1663-4446$

ISSN : $1663-4446$

Éditeur

Librairie Droz

Édition imprimée

Date de publication : 15 mai 2017

Pagination : 264-267

ISSN : 0048-8046

Référence électronique

Anne Cadoret, "Enric PORQUERES I GENE, Individu, personne et parenté en Europe », Revue européenne des sciences sociales [En ligne], 55-1 | 2017, mis en ligne le 17 novembre 2016, consulté le 19 janvier 2021. URL : http://journals.openedition.org/ress/3695; DOI : https://doi.org/10.4000/ress.3695

Ce document a été généré automatiquement le 19 janvier 2021.

(c) Librairie Droz 


\title{
Enric PORQUERES I GENE, Individu, personne et parenté en Europe
}

\author{
Anne Cadoret
}

\section{RÉFÉRENCE}

Enric PORQUERES I GENE, 2015, Individu, personne et parenté en Europe, Paris, Éditions de la Maison des sciences de l'homme, $294 \mathrm{p}$.

1 Individu, personne et parenté en Europe: titre étrange, car existe-t-il une différence sémantique entre individu et personne? Les définitions du dictionnaire (voir le Nouveau Petit Robert de la langue française, 2009) nous donnent, pour le mot « individu », deux grands sens, après en avoir situé l'origine (vient du latin, individuum, soit corps indivisible) : tout d'abord, celui de tout être formant une unité distincte dans une classification; puis, celui d'un corps organisé vivant d'une existence propre et qui ne saurait être divisé sans être détruit. Les définitions pour le mot " personne » (du latin persona, soit masque d'acteur, puis rôle et caractère, et enfin individu) sont beaucoup plus imprécises. Elles renvoient soit à la notion d'individu de l'espèce humaine (homme, mortel, quelqu'un, etc.), soit à un individu particulier. Quant à la parenté, il s'agit du rapport entre personnes descendant les unes des autres, ainsi que d'un rapport équivalent établi par la société comme la parenté adoptive ou la parenté par alliance, ou encore d'un ensemble abstrait du groupe de parents d'un individu particulier. La différence à laquelle Enric Porqueres se réfère par son titre, Individu, personne et parenté, se situerait alors entre l'unité distincte d'une classification et l'être humain. L'objet de son livre serait de saisir la manière dont l'être humain, cet homme (ou femme) mortel(le) prolonge son ascendance en s'y inscrivant tout en s'y différenciant; de comprendre comment cet être mortel se reproduit et reproduit son groupe par l'acte sexuel et l'alliance, la procréation et la filiation.

2 Effectivement, Porqueres prend « comme point de départ les effets des actes sexuels et matrimoniaux compris comme des moments de redéfinition identitaire dans la 
parenté »(p.25), mais nous prévient aussi que la prohibition sexuelle n'est pas l'équivalent de la prohibition matrimoniale. Ethnologue, il s'intéresse donc à l'alliance et à la filiation, et prend comme terrain de réflexion l'Europe en s'inscrivant dans la longue durée de la civilisation chrétienne. Ethnologue avec un regard d'historien et non de sociologue, il tente de "cerner l'importance des actes individuels dans la dynamique de la parenté » (p. 26) et non les stratégies matrimoniales des groupes sociaux. Il va donc regarder ce jeu entre l'alliance et la filiation, ce mouvement entre l'ouverture à du nouveau et le repli dans l'entre soi, au plus proche du même en en retenant les variables comme l'amour, le sang, le nom, le gène ; et tout cela en fonction des grandes époques historiques.

3 Voyons la construction de ce livre. Son auteur, dès la première page de son introduction, remarque " qu'il est d'usage d'évoquer la place importante que l'individu occupe au sein de la parenté occidentale et d'opposer radicalement les sociétés accordant la primauté au poids moral du groupe aux sociétés contemporaines fondées sur la valeur individuelle.» (p. 13). Il remet en cause cette coupure, comme d'ailleurs d'autres anthropologues sur les travaux desquels il s'appuie (Arthur M. Hocart, Edmund Leach, Rodney Needham, etc.) et rappelle, d'une part, que la parenté (kinship) déborde les groupes de filiation (descent) et, d'autre part, que les individus, en tant que personnes inscrites dans une cosmologie (voir les travaux de Françoise Héritier à ce sujet), produisent eux-mêmes de nouvelles entités de parenté. Une fois située sa démarche, il va avancer dans sa démonstration en sept grands chapitres: les trois premiers - "Le jeu des renvois au commencement", "Sacralité du choix matrimonial », "Ordre généalogique et actes matrimoniaux » - nous plongent dans la construction de cet agencement entre l'alliance et la filiation; les trois derniers nous conduisent à la situation actuelle - «La modernité contre l'individu », «La parenté négligée ", «Relation et transcendance à l'époque de l'embryon-individu »; quant au quatrième chapitre, "Cum fuga», c'est une réflexion sur l'espace de liberté entre l'individu et son groupe.

4 Porqueres ouvre son premier chapitre en mettant en exergue un passage de l'Épître aux Éphésiens de Paul qui nous rappelle que l'homme doit quitter son père et sa mère pour s'attacher à sa femme et ne faire avec elle qu'une seule chair. Aimer sa femme revient à s'aimer soi-même et Porqueres remarque que ce rapport entre l'individu et lui-même en tant que cause première de toutes les relations avec son entourage s'inscrit dans le courant philosophique du stoïcisme. La place du corps, à travers la copulation hétérosexuelle, revient en force dans le deuxième chapitre avec le rôle de la sacralité du choix matrimonial et les deux questions suivantes : 1) Quels types de relation sont concernés par cette sacralité ? Le concubinage en fait-il partie? Faut-il prendre en considération la condition sociale des amants? 2) Quels sont les moments essentiels aux relations entre l'homme et la femme qui donnent toute sa force à cette sacralisation: les fiançailles (promesse du futur), l'échange de paroles du présent (promesse du présent) ou l'union sexuelle? Un nouvel impératif apparaît: la constatation par un prêtre, et non par un parent, du libre accord des contractants. Le mariage acquiert alors une dimension volitive. Mais alors, comment transformer ces liens électifs en liens d'appartenance, surtout lorsque se développe la filiation cognatique ? Se forme une naturalisation du passé par le recours à de très longues (et imaginées) généalogies. La référence au sang permet de remonter à un ancêtre fondateur et de développer l'idée de "races maudites» comme, par exemple, les Caqueux de Bretagne, les Morisques de la péninsule ibérique, les Xuetes (Juifs 
convertis) de Majorque, au sujet desquels Porqueres écrit des pages savoureuses, montrant tout le jeu des alliances matrimoniales pour chaque groupe afin de rester au plus près de sa définition - processus de naturalisation des identités - tout en restant intégré à un groupe plus large. Les familles ne sont pas des groupes monolithiques et les divers membres d'une fratrie, par leurs choix personnels, donnent une dynamique à l'histoire de la famille. Cet ordre généalogique et ce contrôle des mariages ne sont pas toujours acceptés par les jeunes gens qui utilisent l'arme de la fugue pour échapper à la volonté de leurs parents contraire à leurs désirs ; et les représentants de l'Église sont là pour recueillir le consentement des nouveaux époux. Le concile de Trente réaffirme le caractère consensuel du lien matrimonial.

Comment, donc, trouver une adéquation entre la volonté des parents et le consentement des enfants lors de ce moment de leur vie où ils quittent le giron de leurs familles d'origine afin de fonder leur famille de procréation (pour reprendre une distinction sociologique entre ces deux types de famille) ? Si, dans cette réflexion sur la combinaison entre individu, personne et parenté, nous avons pu percevoir un premier moment marqué par la progression de l'affirmation juridique du caractère prioritaire et suffisant du consentement mutuel des contractants sur toute autre considération matrimoniale émanant de leurs familles, puis voir les effets de la position du droit canon sur les comportements des individus, avec l'époque moderne, se met en place toute une rhétorique de l'ordre public fondée sur une analogie entre république et famille. Il ne faudrait pas que le pouvoir séculier (celui des parents et de leur amour de leur généalogie) déborde le pouvoir ecclésiastique (avalisant une alliance des enfants refusée par leurs parents); ni, d'ailleurs, a contrario, que le pouvoir ecclésiastique mette à mal le pouvoir séculier des parents. L'harmonie entre ces deux pouvoirs passera par l'État (catholique) qui va préserver la tranquillité des familles et renforcer le pouvoir du paterfamilias. "L'entrée dans la modernité, et notamment l'époque des Lumières, voit les États bureaucratiques multiplier des mesures qui visent à limiter le degré d'autonomie individuelle dans la sphère matrimoniale, par définition source de parenté. » (p. 199). Les liens de parenté seraient-ils devenus une affaire privée, limitée à la sphère familiale, la parenté serait-elle négligée ? Serait-elle le «grand refoulé de la modernité » comme se le demande Joan Bestard que cite Porqueres? Puis, une nouvelle préoccupation marque le $\mathrm{xIX}^{\mathrm{e}}$ siècle : «Si auparavant le sang de la parenté s'identifiait surtout avec le substrat de la transmission héréditaire qui véhiculait l'amour entre les êtres apparentés, désormais il s'impose comme le siège d'une identité référée à la nature. » (p. 221). Les préoccupations quant aux « races maudites » s'estompent.

6 Nous arrivons alors à l'époque contemporaine et à la possibilité techno-médicale de fabriquer et transférer un embryon. La personne, divisible dans d'autres sociétés (Porqueres nous renvoie aux travaux de Marilyn Strathern à ce sujet), est synonyme de l'individu, soit ce « corps organisé vivant d'une existence propre et qui ne saurait être divisé sans être détruit", pour reprendre la définition du Nouveau Petit Robert. La personne, érigée en sujet de droit, serait identifiée à l'embryon. Le sang est devenu le gène et la recherche des origines concerne la recherche de sa propre identité, de son soi. La personne transformée en individu sort d'un ensemble de parenté lui préexistant pour constituer sa propre parenté. La parenté deviendrait-elle seulement la parentèle ? Avec, cependant, toujours comme limite à cette individualisation de la parenté, les interdits d'inceste. 
7 De ce compte-rendu bien partiel, vu la richesse mais aussi la grande complexité des réflexions que nous livre Porqueres, je voudrais conclure par la remarque suivante : $\mathrm{Si}$ Porqueres analyse dans ces 294 pages la place de l'individu et de la personne dans la parenté en Europe, s'il s'arrête longuement sur le rôle de la copulation hétérosexuelle dans l'alliance et la manière dont les cartes de la parenté peuvent en être rebattues, il ne parle absolument pas du corps, comme le fait, par exemple, Maurice Godelier dans ses Métamorphoses de la parenté de 2004. Il n'est pas non plus intéressé par la question du genre. Nous ne pouvons certes pas lui en faire le reproche, car ce n'est pas son angle d'attaque. En fait, ne reprendrait-il pas, en les ouvrant à notre $\mathrm{xxI}^{\mathrm{e}}$ siècle et aux sociétés européennes, les discussions des années 1950-1960 d'Edmund Leach ou Rodney Needham ? À cet égard, pour aussi ardu qu'il soit, ce livre n'en offre pas moins un regard stimulant.

\section{AUTEURS}

ANNE CADORET

Paris, CNRS - Cerlis 